\title{
Coral Reef Benthic Video Surveys Facilitate Long-Term Monitoring in the Commonwealth of the Northern Mariana Islands: Toward an Optimal Sampling Strategy ${ }^{1}$
}

\author{
Peter Houk ${ }^{2,3,4}$ and Robert Van Woesik ${ }^{2}$
}

\begin{abstract}
This study describes a step-by-step process used to design an effective benthic video survey component of the Commonwealth of the Northern Mariana Islands long-term monitoring program. Documenting abundance of major benthic groups at relatively large spatial scales, at the appropriate localities, can empower monitoring programs with the capacity to detect changes over time and assess whether management practices are working. Most pertinent to any long-term monitoring program is the overriding question: do we have enough information, or statistical power, to detect changes if changes occur? To assess the power of our benthic video surveys to detect change in coral cover and diversity we varied (1) transect lengths, (2) number of transects, (3) number of frames per transect, and (4) number of data points per frame. Five replicated 50-m transects yielded the most consistent estimates with the highest statistical power, compared with more numerous replicates of shorter $(35-\mathrm{m}$ and $15-\mathrm{m})$ transects. Increasing the number of frames analyzed per 50-m transect yielded greater power than increasing the number of data points per frame, but increasing the number of data points was more effective at estimating species richness. The greatest power of detecting a change in the benthos at each site, within a feasible sampling period, was evident using 5 by $50 \mathrm{~m}$ random transects, extracting 60 frames per transect, and analyzing five data points on each frame. This optimal sampling strategy was tested at 23 other long-term monitoring sites and yielded $90 \%$ power to detect a $20-30 \%$ relative change in dominant benthos abundance estimates (benthos $>20 \%$ coverage). Our study addresses the sampling unit, accuracy, and ways to improve estimates, but this does not remove the onus of concisely stated questions for monitoring programs pertaining to management.
\end{abstract}

LONG-TERM MONITORING of coral reefs requires appropriate strategies that account for the spatial arrangement of organisms and should yield accurate abundance estimates with sufficient statistical power to detect (a

\footnotetext{
${ }^{1}$ Manuscript accepted 30 June 2005.

2 Department of Biological Sciences, Florida Institute of Technology, 150 West University Boulevard, Melbourne, Florida 32901.

${ }^{3}$ Commonwealth of the Northern Mariana Islands, Division of Environmental Quality, P.O. Box 501304, Saipan, Mariana Islands 96950.

${ }^{4}$ Author for correspondence (e-mail: phouk@fit.edu).
}

Pacific Science (2006), vol. 60, no. 2:177-189

(C) 2006 by University of Hawai'i Press

All rights reserved desired level of) change (Aronson et al. 1994, Green and Smith 1997, Page et al. 2001). Many techniques are available to aid researchers in these assessments. Some in situ methods include line-intercept transects (Loya 1978), point quadrats (Chiappone et al. 2001), and belt transects (Littler et al. 1997). In comparison with in situ methods, capturing images underwater increases field efficiency (Foster et al. 1991) and increases the spatial extent of reef coverage, while maintaining a useful taxonomic resolution (Carleton and Done 1995, Vogt et al. 1997). Because of their accuracy, efficiency, and simplicity, video surveys are used in many coral reef monitoring programs (Aronson et al. 1994, Vogt et al. 1997, Page et al. 2001, Rogers and Miller 2001, Brown et al. 2004). 
Coral cover, diversity, and population density estimates will vary depending on the methodology used for data collection (Weinberg 1981, Rogers et al. 2002, Brown et al. 2004). Similarly, for benthic video surveys, relative abundance estimates and the statistical power to detect change will vary according to (1) the number of data points analyzed in each paused (video) frame, (2) the number of frames analyzed in each transect, (3) the number of replicate transects used, and (4) the length of transect. Studies and monitoring programs vary with respect to these criteria but vary also with respect to the question being addressed. For example, it may be useful to analyze a large number of points on any one frame for estimates of coral cover but problematic using the same high number of points to examine the number of colonies because of the increased likelihood of autocorrelation (i.e., counting the same colonies more than once) (Carleton and Done 1995). Similarly, rapid ecological assessments are less concerned about the statistical power of detecting a change than long-term monitoring programs (Andrew and Mapstone 1987).

Besides the various techniques available for data collection, monitoring programs must also decide on the degree of site permanency and at what level to randomize. A time series of permanent photoquadrats provides valuable insight into population dynamics but lacks general information regarding the spatial arrangement of organisms within the community as a whole (Green and Smith 1997). One benefit of permanent, repeatedmeasure sampling is the elucidation of recruitment, death, and survival rates of the organisms under question (Wilson and Bossert 1971). However, no confidence measure is available for upscaling the results from a fixed location to an entire reef community, which may bias a spatial interpretation (Davidson 1997).

Fully randomized designs provide community characterizations that account for the spatial arrangement of individuals in the communities (Green and Smith 1997). High statistical power achieved through randomized designs means that any measured change is indicative of a change in the community, yet sampling effort may need to be tremendously intensive (Aronson et al. 1994, Green and Smith 1997).

At each study site the Australian Institute of Marine Science's (AIMS) Long-Term Monitoring Program uses a fixed, unstratified sampling design consisting of 5 by $50 \mathrm{~m}$ transects, 40 frames within each transect, and five data points from each frame (Page et al. 2001). The Hawai'i Coral Reef Assessment and Monitoring Program (CRAMP) uses a fixed, stratified sampling design consisting of 10 by $10 \mathrm{~m}$ transects, 20 frames per transect, and 50 data points per frame (Brown et al. 2004). Carleton and Done (1995) recognized the potential implications of autocorrelation within each frame and therefore increased the number of frames while analyzing only one data point per frame. Aronson et al. (1994) used a random, unstratified design consisting of 10 by $25 \mathrm{~m}$ transects, 50 frames within each transect, and 10 data points for each frame for Caribbean forereefs. Clearly, different reef systems and studies may require different sampling designs, transect lengths, transect replicates, numbers of frames, and numbers of data points to achieve a desired power to detect change of different benthic organisms (Table 1). Here, we present a study that was used to determine an appropriate benthic video survey design for the Commonwealth of the Northern Mariana Islands long-term monitoring program. The goal of this study was to design a scheme that will elucidate a useful sampling unit with sufficient power $(90 \%)$ to detect a (relative) $20-30 \%$ change in dominant benthos cover over time. This study focused on a general approach used to select appropriate transect lengths, transect replicates, number of frames, and number of data points for benthic video surveys at each site. It did not address the need to replicate sites within each combination of time, location, and management regime. Because the study was primarily concerned with the spatial distribution and variance in the cover of dominant organisms, benthic video surveys were complemented with point quadrat coral community surveys (Houk et al. 2005), coral recruitment belt transects, overall diversity assessments, and permanent photo- 
TABLE 1

Summary of Comparable Coral Reef Monitoring Program Designs

\begin{tabular}{lccccc}
\hline \hline & \multicolumn{1}{c}{$\begin{array}{c}\text { Number } \\
\text { Survey } \\
\text { Design }\end{array}$} & $\begin{array}{c}\text { Number of } \\
\text { (m) of } \\
\text { Transect }\end{array}$ & $\begin{array}{c}\text { Extracted } \\
\text { Frames } \\
\text { (per Transect) }\end{array}$ & $\begin{array}{c}\text { Number of } \\
\text { Data Points } \\
\text { Analyzed } \\
\text { (per Frame) }\end{array}$ & Citation \\
\hline $\begin{array}{c}\text { Australian Institute of } \\
\text { Marine Science (AIMS) } \\
\text { reef monitoring }\end{array}$ & $\begin{array}{c}\text { Fixed, } \\
\text { unstratified }\end{array}$ & $5 \times 50$ & 40 & 5 & Page et al. 2001 \\
$\begin{array}{c}\text { Hawaii Coral Reef Assessment } \\
\text { and Monitoring Program } \\
\begin{array}{c}\text { (CRAMP) } \\
\text { Caribbean forereef } \\
\text { monitoring }\end{array}\end{array}$ & $\begin{array}{c}\text { Fixed, } \\
\text { stratified }\end{array}$ & $10 \times 10$ & 20 & 50 & Brown et al. 2004 \\
$\begin{array}{c}\text { Commonwealth of the } \\
\text { Northern Mariana Islands } \\
\text { reef monitoring }\end{array}$ & $\begin{array}{c}\text { Random } \\
\text { Random, } \\
\text { unstratified }\end{array}$ & $10 \times 25$ & 50 & 10 & Aronson et al. 1994 \\
\hline
\end{tabular}

quadrats to provide ecological depth beyond "cover." Together, these data are used to provide assessments of reef "health" and change at long-term monitoring sites in the Commonwealth of the Northern Mariana Islands (CNMI).

\section{MATERIALS AND METHODS}

\section{Study Area}

This study was undertaken in the southern Mariana Islands (CNMI), located at $145^{\circ} \mathrm{E}$ (longitude) and extending latitudinally from $14^{\circ}$ to $15^{\circ} \mathrm{N}$ (Figure 1 ). The geologically distinct southern islands are composed mainly of raised Miocene and Pleistocene limestone (Cloud et al. 1959). Data were collected from the forereef slopes of the islands of Rota, Aguijan, Tinian, and Saipan in accordance with CNMI's marine monitoring program. The physical environment of the CNMI is characterized by exposure to seasonal trade wind-driven waves and frequent typhoons. These conditions result in the dominance of corals and coralline and turf algae on most reef slopes.

\section{Survey Design}

Initially, benthic videos were taken from a reef slope community $8 \mathrm{~m}$ deep on the north- western coast of Aguijan (AGU 2, Figure 2). This site represents one of the 24 long-term monitoring sites surveyed by the CNMI marine monitoring team (Houk et al. 2002). Coral cover data were used to determine relationships between statistical power and transect length, number of replicate transects, number of frames per transect, and number of data points per frame, at the AGU 2 site. A survey design based upon preliminary findings was used at the other 23 localities (Figure 2). This design was evaluated by calculating the resultant power from dominant benthos estimates, including hard and soft corals, zoanthids, turf algae, coralline algae, and macroalgae, whose absolute abundance was $\geq 20 \%$. Back calculations for the appropriate number of transects required to detect various levels of change were based upon these categories.

\section{Power Analyses}

Statistical power provides a measure of confidence (a probability) that a false null hypothesis will be correctly rejected (Zar 1999). In other words, we wish to detect a change should it occur. Here, the null hypothesis was that there is no change in benthos abundances at these reefs over time. Power analysis was carried out to assess which datacollection schemes provide enough power to 


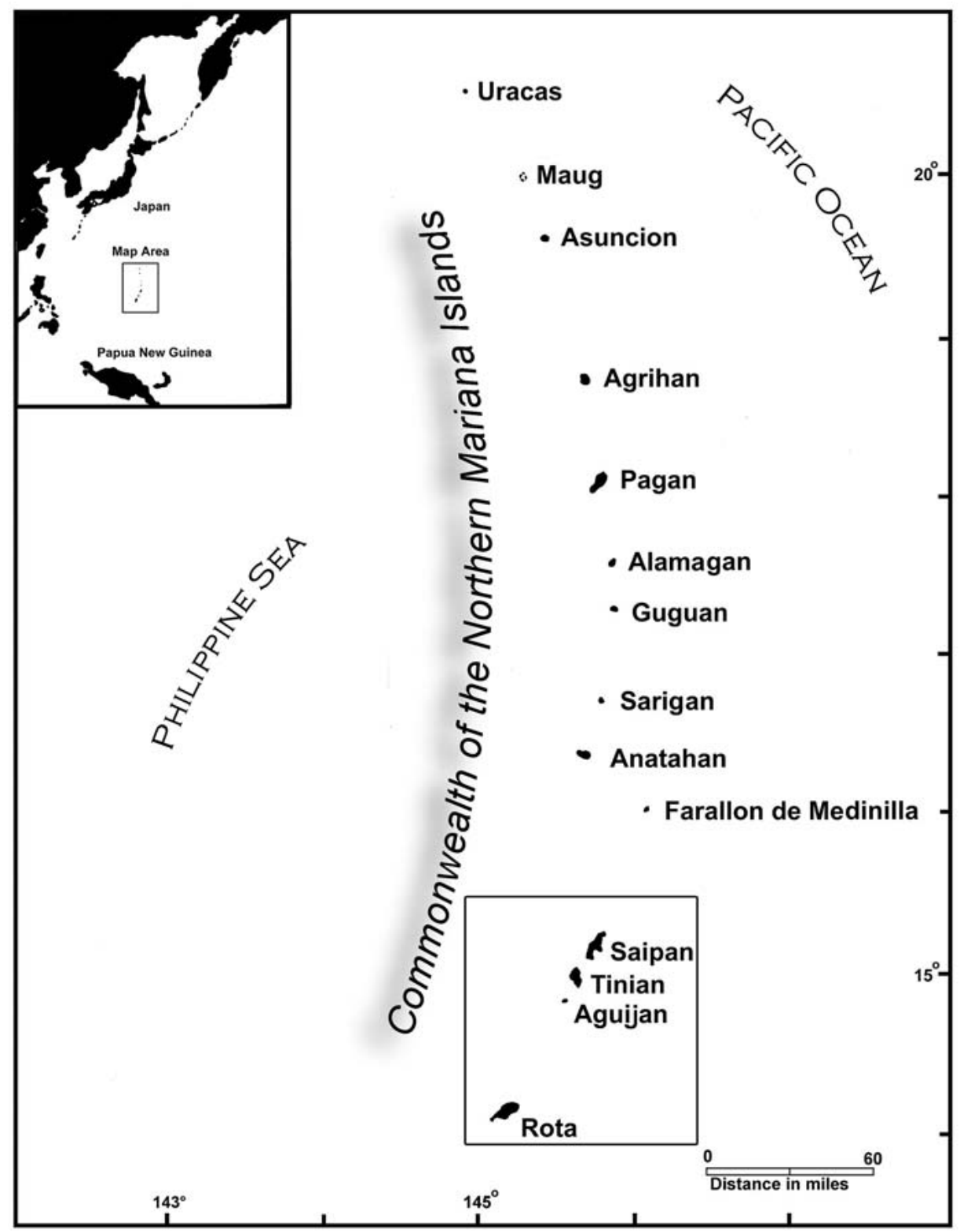

Figure 1. A map of the Commonwealth of the Northern Mariana Islands, with study area enclosed in box.

detect change, so that a false null hypothesis will be correctly rejected. Power calculations yielded a probability $(\beta)$ of encountering a type II error (incorrect acceptance of a false null hypothesis) based upon the number of and variance among replicate transects (Zar 1999). Power was calculated using

$$
t_{\beta(1), v}=\frac{\delta}{\sqrt{\frac{s^{2}}{n}}}-t_{\alpha, v}
$$

where $t_{\alpha, v}$ is the probability of type I error (Student's $t$ value), $\delta$ is the value of detectable change desired, $n$ is the sample size, $v=n-1$ 


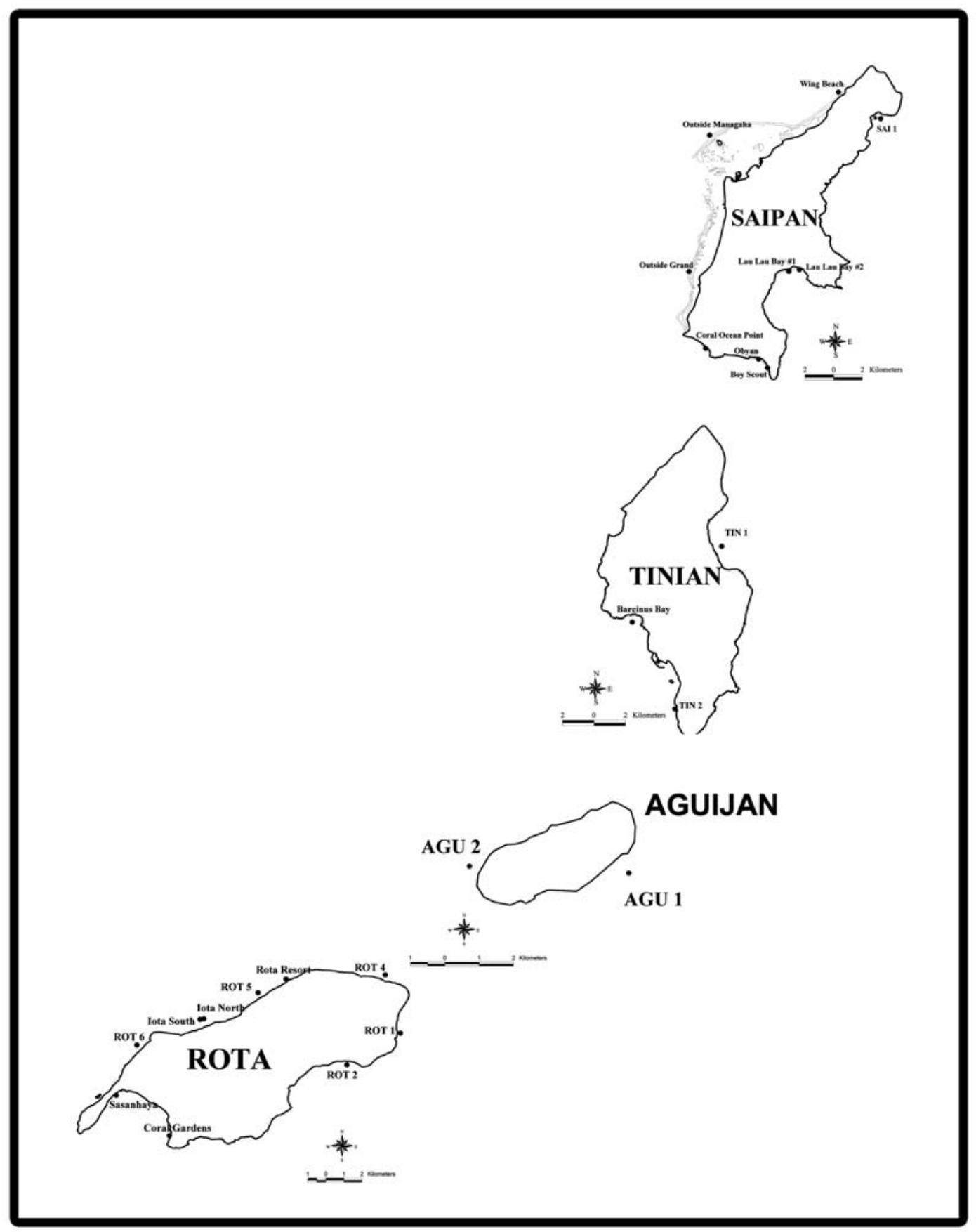

FIGURE 2. Long-term monitoring sites currently established by the CNMI marine monitoring program. Distance between islands is not to scale. 
degrees of freedom, $s^{2}$ is the sample estimate of the variance, and $t_{\beta, v}$ yields the resultant power (or 1 - type II error). To calculate the number of transects required to detect a specific change in the reef, we used

$$
n=\frac{s^{2}}{\delta^{2}}\left(t_{\alpha, v}+t_{\beta(1), v}\right)^{2}
$$

Power curves were created by solving equation 2 for $n$ and inputting different values of $\beta$ to yield the appropriate number of replicate transects required to achieve a desired level of statistical power.

\section{Data Collection}

Benthic videos were taken in June 2002 at the initial site and from July 2002 to July 2003 at 23 other monitoring sites. Video belt transects were completed for 5 by $50 \mathrm{~m}, 7$ by 35 $\mathrm{m}$, and 15 by $15 \mathrm{~m}$ transects laid end to end following a $\sim 8$-m depth contour. An underwater digital video camera with a red filter was used to record belt transects at a consistent width. A calibration rod that extended from the camera minimized variation in transect width. For each transect, a scuba diver swam the video camera at a constant speed to yield a 50 by $0.5 \mathrm{~m}$ belt in a period of $5-6$ min, $\sim .15 \mathrm{~m} / \mathrm{sec}$.

For the preliminary site, digital video recordings were processed at the Florida Institute of Technology's Information and Technology Center. Initial processing included the extraction of JPEG images (or frames) from the video clip (or transect) at desired intervals. Random points were overlaid on each frame using Pointcount '99 software (http://www.cofc.edu/ coral/pc99/pc99 .htm). A factorial setup was used to extract data for different transect lengths and number of transects (Figure 3a). This design examined the effect of transect length and replication on statistical power, while keeping the number of frames consistent. All data were collected at similar (one frame per $5 \mathrm{sec}$ ) intervals, with different numbers of data points $(5,10$, and 15$)$ per frame. This yielded estimates, variances, and power associated with 5 by $50 \mathrm{~m}, 7$ by $35 \mathrm{~m}$, and 15 by $15 \mathrm{~m}$ transects (respectively, $250 \mathrm{~m}, 245 \mathrm{~m}$, and $225 \mathrm{~m}$ total length). These analyses led to the selection of 5 by $50 \mathrm{~m}$ transects, which were then subjected to further factorial testing to determine the optimal number of frames per transect and number of data points per frame (Figure $3 b)$. Five 50-m transects were analyzed using 20 frames (one per $15 \mathrm{sec}$ ), 40 frames (one per $7.5 \mathrm{sec}$ ), and 60 frames (one per $5 \mathrm{sec}$ ) for each transect. In each case a different number of data points were analyzed: 5, 10, and 15 per frame.

\section{Community Richness}

Margalef's species richness index was used as a measure of coral diversity, taking into account how diversity was distributed throughout each transect line (Clarke and Warwick 2001). Margalef's index describes how evenly the percentage cover was spread over various coral genera for any given 50-m transect; a high Margalef's $d$-statistic suggests that coral cover estimations do not overemphasize dominant coral genera because they also include less abundant and smaller corals. Calculations were made using

$$
D=(S-1) / \ln (n)
$$

where $D=$ Margalef's index, $S=$ total number of species, and $n=$ number of individuals.

\section{RESULTS}

Transect length influenced statistical power (Figure 4); 50-m-long transects consistently showed the highest power (Figure 4c). Shorter transects showed considerable variation in accordance with the number of data points analyzed. Both $35-\mathrm{m}$ and $15-\mathrm{m}$ transects had unexpected, inconsistent trends, as increasing the number of data points from 10 to 15 resulted in lower power. Increasing the number of frames analyzed per $50-\mathrm{m}$ transect was a more effective way to achieve greater power compared with increasing the number of data points per frame (Figure 5). Regardless of the number of data points analyzed, 60 frames per 50-m transect had the greatest power of detecting change in the cover of dominant organisms. Increasing 

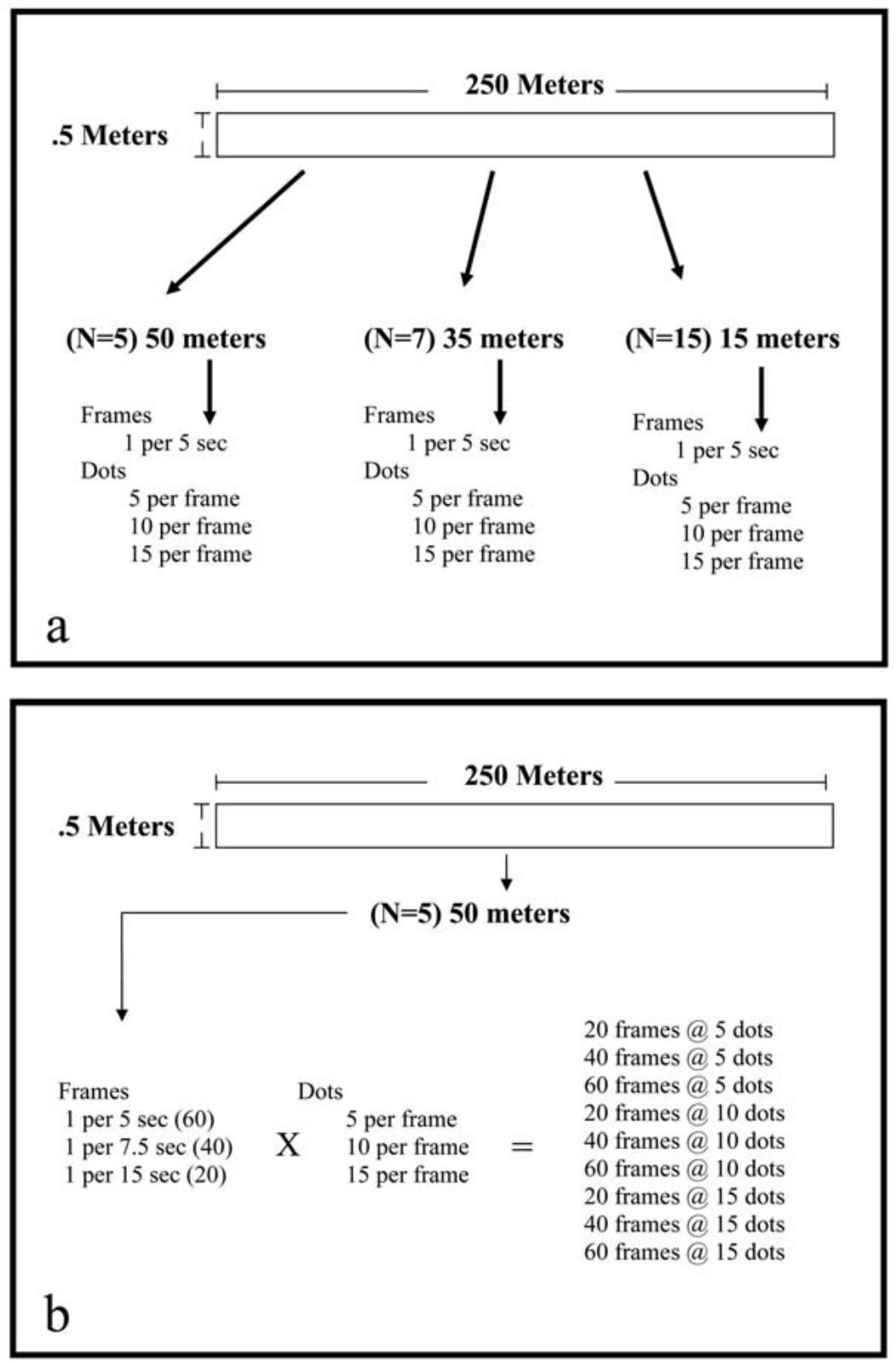

FIgURE 3. Schematic representation of the factorial design to estimate the power of detecting change using (a) different transect lengths (for the same number of frames), and (b) different frames per transect and data points per frame for 5 by $50 \mathrm{~m}$ transects. 

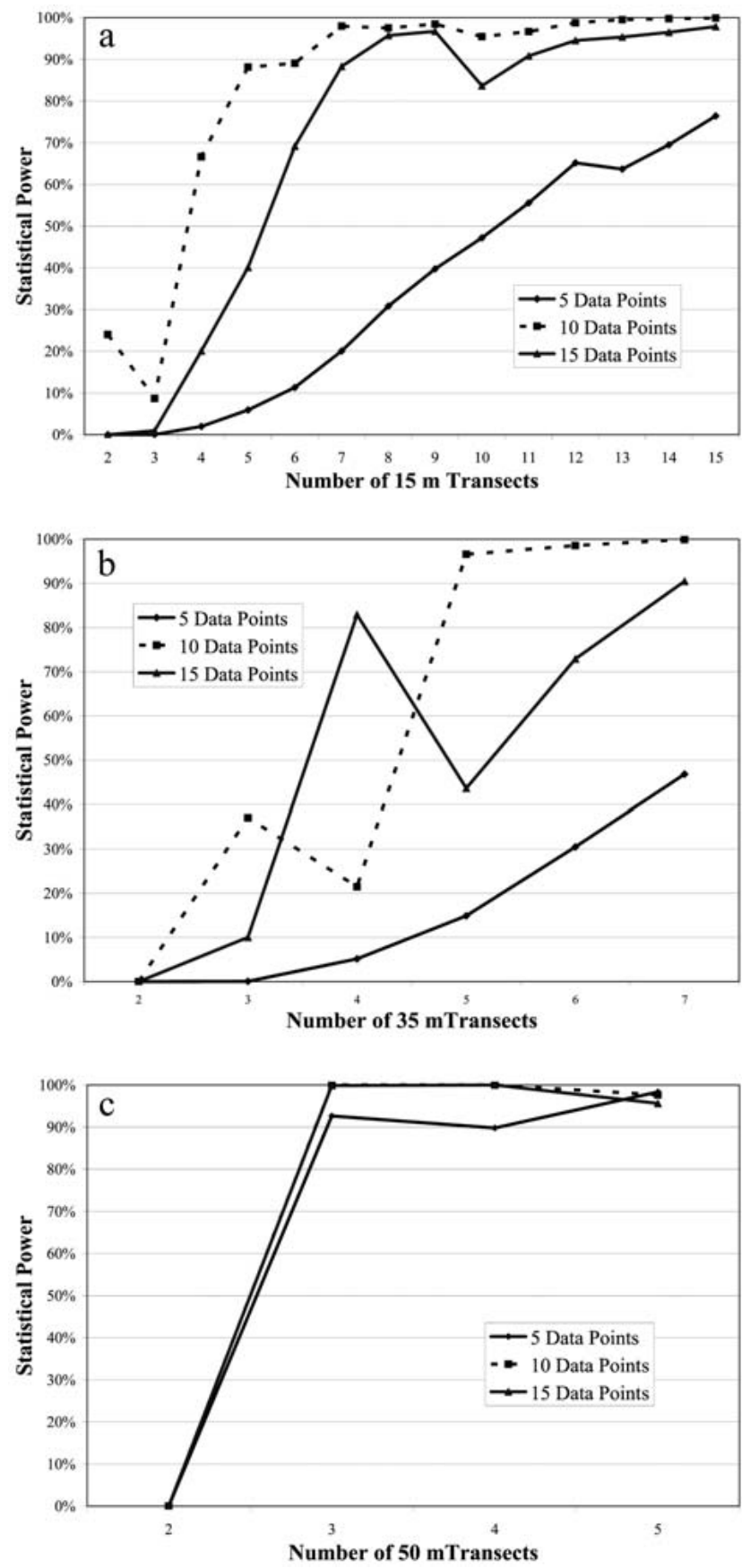

FigURe 4. Resultant statistical power to detect a $20 \%$ change in coral cover analyzing 5,10 , and 15 data points: (a) using 15 by $15 \mathrm{~m}$ transects; (b) using 7 by $35 \mathrm{~m}$ transects; (c) using 5 by $50 \mathrm{~m}$ transects. 


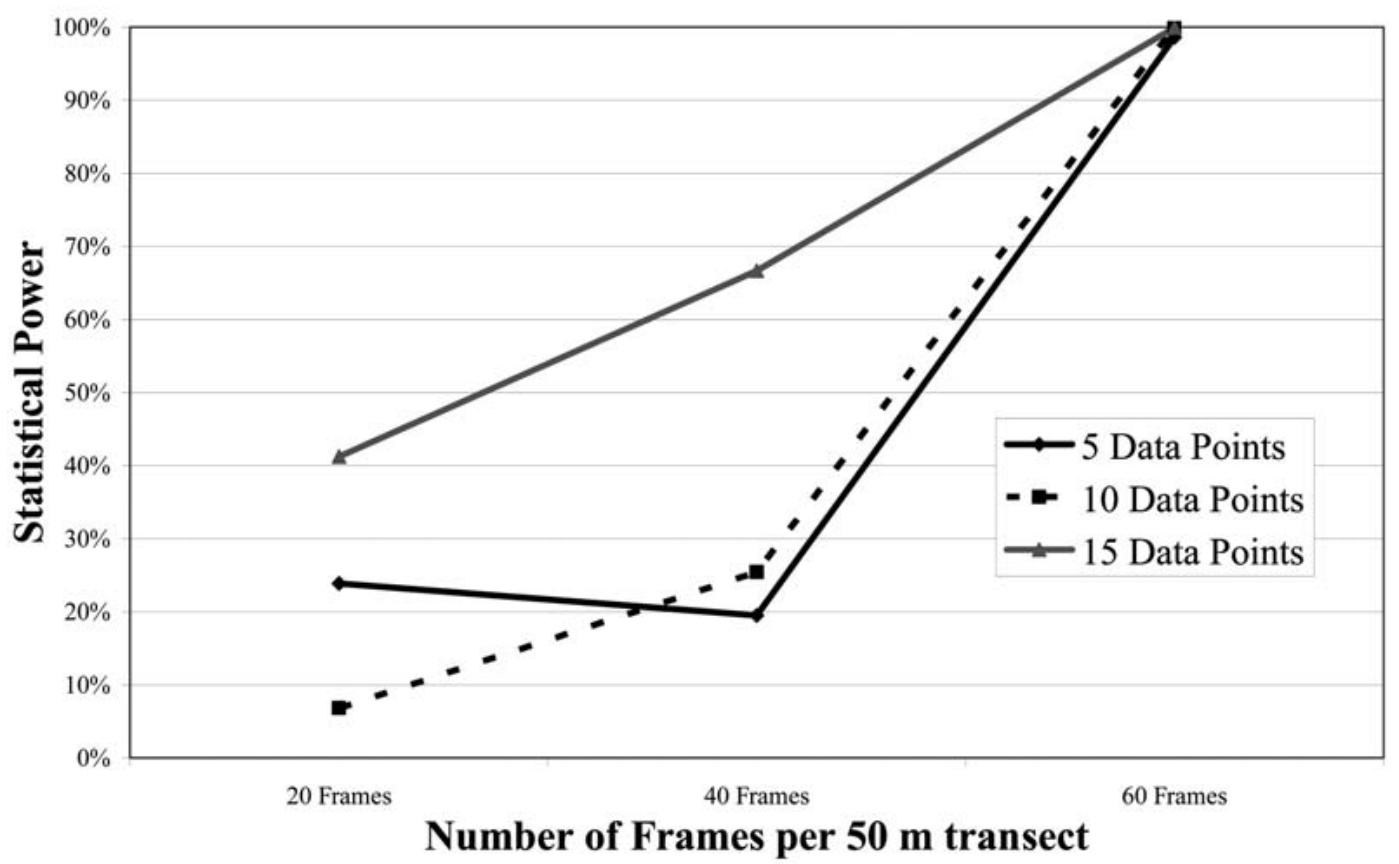

FIGURE 5. Resultant statistical power to detect a $20 \%$ change in coral cover using 5 by $50 \mathrm{~m}$ transects while varying the numbers of frames and data points.

the number of data points while decreasing the number of frames (e.g., 20 frames with 15 data points) also resulted in higher power; however, inconsistent trends were found (Figure 5). Analysis of 60 frames with five data points is the most time-efficient method that provided the highest power.

Coral species richness estimates showed two trends with respect to the number of frames and data points used (Figure 6). There was a large increase in richness between 5 and 10 data points, followed by a lower increase between 10 and 15 data points. There was also a positive trend noted when the number of frames was increased. Richness increased most between 20 and 40 frames, followed by a smaller increase between 40 and 60 frames.

\section{Application of Strategy to Other Localities}

Based upon these findings, power analyses were conducted for the dominant benthos at 23 other long-term monitoring localities using five $50-\mathrm{m}$ transects, 60 frames per tran- sect, and five data points. A 30\% relative change was detectable with $90 \%$ power for all dominant benthos using four 50-m transects (Figure 7). A $20 \%$ relative change was detectable with $75 \%$ power using 5 by $50 \mathrm{~m}$ transects. Back calculations revealed that approximately 8 by $50 \mathrm{~m}$ transects are required to achieve a $90 \%$ power to detect a $20 \%$ relative change (Figure 7).

\section{DISCUSSION}

The primary goal of the benthic video surveys for the CNMI long-term monitoring program is to have approximately $90 \%$ confidence that we can detect a $20-30 \%$ relative change of the dominant benthic organisms. Five 50-m transects with 60 frames per transect at five data points per frame yielded estimates at this desired level for all 24 long-term monitoring sites. Although the benthic dominance varies considerably among localities, all sites supported hard and soft corals, zoanthids, turf algae, coralline algae, and macroal- 


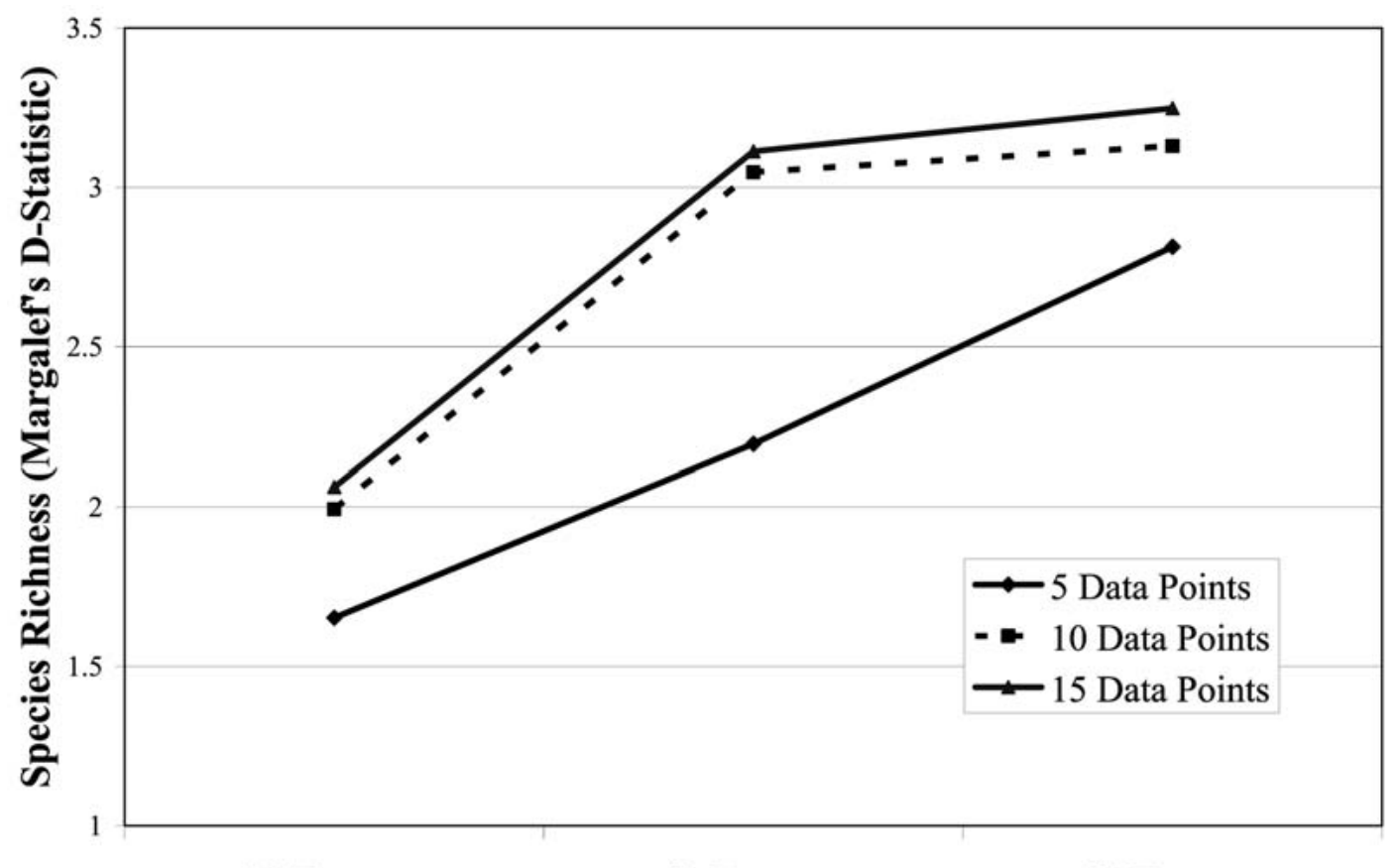

20 Frames

40 Frames

60 Frames

Figure 6. Coral species richness estimates from 5 by $50 \mathrm{~m}$ transects while varying the numbers of frames and data points.

gae. These data answer questions regarding large-scale ecosystem changes, while other complementary methods provide information regarding coral community structure and the dynamics of populations.

Statistical power represents the probability of type II error, or correctly detecting that change has occurred in benthos estimates. This is pertinent to management because disturbances that impact reefs may not be detected if sampling is too light. Yet reefs differ geographically, and using the same sampling strategy may be problematic. For example, long-term monitoring of Caribbean reefs deals with coral cover estimates ranging from 2.8 to $21.2 \%$ (Aronson et al. 1994), significantly lower than $\sim 40 \%$ estimates recorded on reefs in the CNMI. Lower abundances are often accompanied by higher variances, resulting in lower statistical power if sufficient replication is not used to account for these higher variances. Thus, it is not sur- prising that Aronson et al. (1994) detected only a $50 \%$ relative change in coral cover with $90 \%$ power in their video surveys because their variances were equal to or greater than the means $(2.3-59.3)$. The power equation (1) suggests that it is just as easy to detect changes in low but homogenously distributed percentage cover as it is for high cover, suggesting that the spatial variance of the cover often limits desirable power detection.

The goal of the Hawai' $i$ CRAMP program is to detect an absolute change of $10 \%$ in benthos abundance estimates with high ( $\sim 80 \%$ ) power (Brown et al. 2004). At each site eight to ten 10-m fixed transects, 20-30 frames per transect, and 50 data points resulted in the most cost-effective means of achieving the desired goals. Clearly, a fixed survey design increases statistical power, but no measure is placed on whether or not these findings are indicative, or indeed representative, of the larger reef community. Compared 


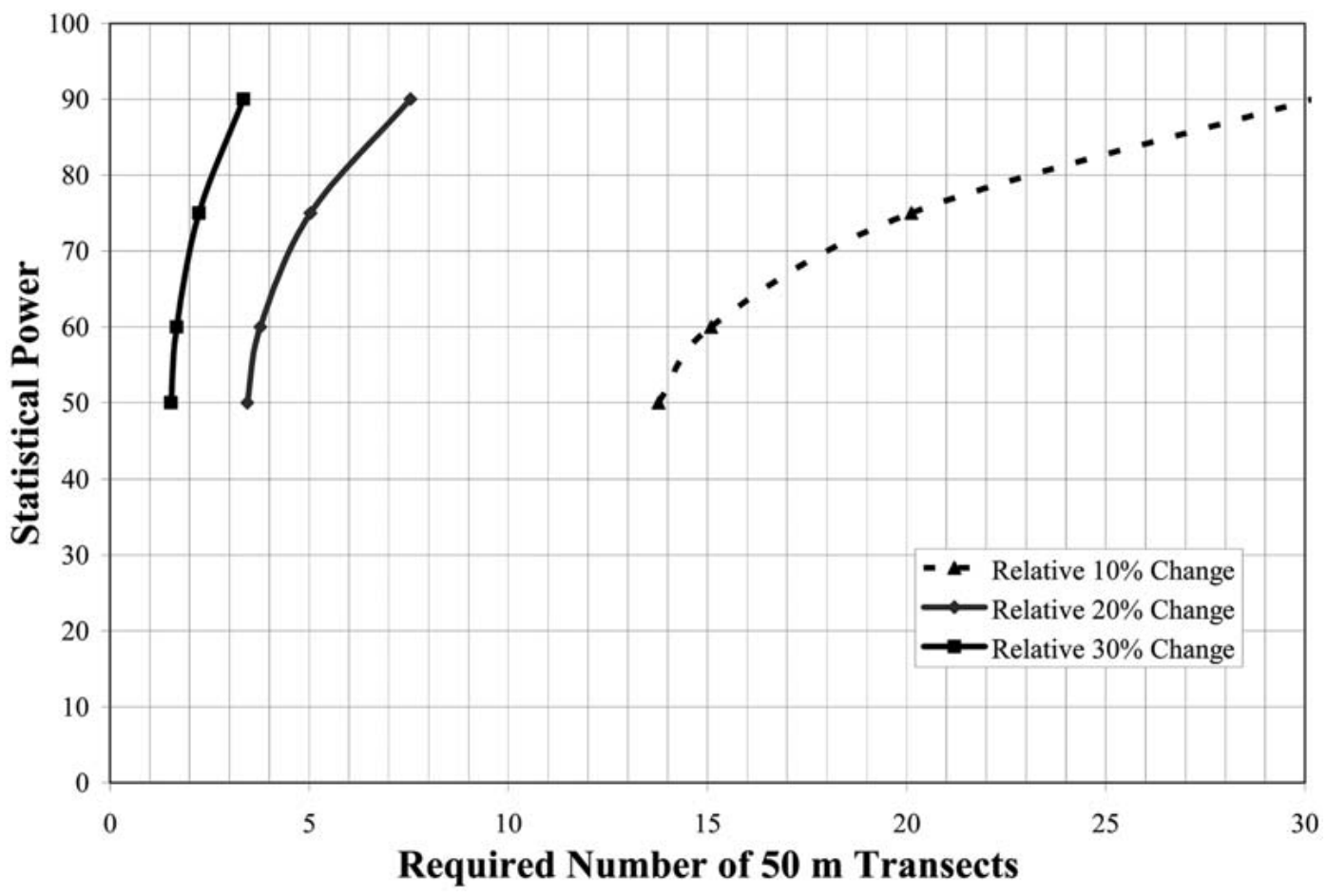

Figure 7. Resultant statistical power for detecting a 20\% change in absolute abundance of dominant benthos at 24 long-term monitoring locations. Back calculations for the required number of $50-\mathrm{m}$ transects are based upon detection of a relative $10 \%, 20 \%$, and $30 \%$ change in benthos abundance at various $\beta$ values.

with our findings, Brown et al. (2004) used a smaller spatial scale $(100 \mathrm{~m}$ versus $250 \mathrm{~m}$ total length) but a much larger number of data points $(10,000$ versus 1,500 data points analyzed per site). Again, intensive sampling within frames is useful for detecting changes in cover estimates but problematic when colony abundance estimates are considered because the same colonies are sampled more than once (i.e., oversampling within frames leads to abundance overestimates).

What is the relationship between the spatial scale and the number of data points analyzed at a site? Here, $90 \%$ power of detecting a relative $20-30 \%$ change was attained when using $50-\mathrm{m}$ transects regardless of the number of data points (Figure 4c). Aronson et al. (1994) found that increasing the number of data points per frame from 5 to 25 , using a sample area equal to that in our study, did not decrease the variance around estimated coral cover means for Caribbean reefs. In the present study, increasing the number of frames within 50-m transects was a more effective means of achieving desired power than increasing the number of data points within frames (Figure 5). Brown et al. (2004) noticed similar trends; however, only relatively small increases in power were detected. This may be attributed to the larger sample area tested here compared with that sampled by Brown et al. (2004).

Increasing the number of data points per frame will eventually result in autocorrelation (two or more dots recording the same organism), which leads to biased estimates of colony abundance. In theory more data points will fall upon large colonies than upon small coral colonies. This can be defined as unequal levels of autocorrelation between different size classes of corals and has adverse implications for relying entirely upon benthic video 
surveys for monitoring. Extracting more frames, while lowering the number of data points per frame, increases the spatial coverage of the survey design and decreases the risk of associated bias.

This study showed that lowering the number of data points analyzed per frame decreased evenness estimates because lesscommon and smaller corals were not adequately represented. Similarly, other studies using one and five data points per frame have shown that corals with low colony abundance have larger standard deviations compared with their mean percentages (Carleton and Done 1995, Ninio and Meekan 2002). Here, considerably more effort (more data points per frame) would be required to approach saturation in richness estimates. Therefore, benthic video surveys are an essential component of CNMI's monitoring program because they document abundance and change of all major functional groups at relatively large spatial scales but are complemented with quadrat-based coral community surveys and recruitment belt transects to yield an understanding of population dynamics.

\section{ACKNOWLEDGMENTS}

This work could not have been completed without support from the CNMI Division of Environmental Quality, Director John I. Castro Jr.; the CNMI Coastal Resources Management Office, Director Jack Salas; and the USEPA Region IX, CNMI Program Manager Pat Young. The entire CNMI marine monitoring team assisted with field data collection, including Fran Castro, Clarence Igisiar, John Iguel, Carlos Ketebengang, Edson Limes, Marvin Seman, Ben Somol, John Starmer, and Gary Toves. Thanks to Nikki Hoier for assistance with video processing and John Starmer for reviews of various drafts of the manuscript.

\section{Literature Cited}

Andrew, N. L., and B. D. Mapstone. 1987. Sampling and the description of spatial pattern in marine ecology. Mar. Biol. Annu. Rev. 25:39-90.

Aronson, R. B., and D. W. Swanson. 1996. Video surveys of coral reefs: Uni- and multivariate applications. Proc. 8th Int. Coral Reef Symp. 2:1441-1446.

Aronson, R. B., P. J. Edmunds, W. F. Precht, D. W. Swanson, and D. R. Levitan. 1994. Large-scale, long-term monitoring of Caribbean coral reefs: Simple, quick, inexpensive techniques. Atoll Res. Bull. 421:119.

Brown, E., E. Cox, P. Jokiel, K. Rodgers, W. Smith, B. Tissot, S. L. Coles, and J. Hultquist. 2004. Development of benthic sampling methods for the Coral Reef Assessment and Monitoring Program (CRAMP) in Hawai'i. Pac. Sci. 58:145158.

Carleton, J. H., and T. J. Done. 1995. Quantitative video sampling of coral reef benthos: Large-scale application. Coral Reefs 14:35-46.

Chiappone, M., K. Sullivan-Sealey, G. Bustamante, and J. Tschirky. 2001. A rapid assessment of coral reef community structure and diversity patterns at Naval Station Guantanamo Bay, Cuba. Bull. Mar. Sci. 69:373-394.

Clarke, K. R., and R. M. Warwick. 2001. Change in marine communities: An approach to statistical analysis and interpretation, 2nd ed. PRIMER-E, Plymouth, United Kingdom.

Cloud, P. E., R. G. Schmidt, and H. W. Burke. 1959. Geology of Saipan, Mariana Islands, Part 1. General geology. U.S. Geol. Surv. Prof. Pap. 280.

Davidson, J. 1997. Optimising the use of a video transect technique for the monitoring and rapid ecological assessment of tropical benthic communities. M.S. thesis, James Cook University, Queensland.

Foster, M. S., C. Harrold, and D. D. Hardin. 1991. Point vs. photo quadrat estimates of the cover of sessile marine organisms. J. Exp. Mar. Biol. Ecol. 146:193-203.

Green, R. H., and S. R. Smith. 1997. Sample program design and environmental impact assessment of coral reefs. Proc. 8th Int. Coral Reef Symp. 2:1459-1464. 
Houk, P., B. Bearden, C. Tanaka, F. Castro, and J. Kaipat. 2002. CNMI 305(b) Water quality report. CNMI Division of Environmental Quality, Saipan, Commonwealth of the Northern Mariana Islands.

Houk, P., G. Didonato, J. Iguel, and R. Van Woesik. 2005. Assessing the effects of non-point source pollution on American Samoa's coral reef communities. Environ. Monit. Assess. 107:11-27.

Littler, M. M., D. S. Littler, B. L. Brooks, and K. J. Koven. 1997. A unique coral reef formation discovered on the Great Astrolabe Reef, Fiji. Coral Reefs 16:5154.

Loya, Y. 1978. Plotless and transect methods. Pages 197-217 in D. R. Stoddart and R. E. Johannes, eds. Coral reefs: Research methods. Paris, UNESCO.

Ninio, R., and M. G. Meekan. 2002. Spatial patterns in benthic communities and the dynamics of a mosaic ecosystem on the Great Barrier Reef, Australia. Coral Reefs 21:95-103.

Page, C., G. Coleman, R. Ninio, and K. Osborne. 2001. Surveys of benthic reef communities using underwater video. Longterm monitoring of the Great Barrier
Reef. Standard Operational Procedure No. 7. Australian Institute of Marine Science, Townsville.

Rogers, C. S., and J. Miller. 2001. Coral bleaching, hurricane damage, and benthic cover on coral reefs in St. John, U.S. Virgin Islands: A comparison of surveys with the chain transect method and videography. Bull. Mar. Sci. 69:459-470.

Rogers, C. S., J. Miller, and R. J. Waara. 2002. Tracking changes on a reef in the U.S. Virgin Islands with videography and SONAR: A new approach. Proc. 9th Int. Coral Reef Symp. 2:1065-1071.

Vogt, H., A. R. F. Montebon, and M. L. R. Alcala. 1997. Underwater video sampling: An effective method for coral reef surveys? Proc. 8th Int. Coral Reef Symp. 2:14471452.

Weinberg, S. 1981. A comparison of coral reef survey methods. Bijdr. Dierk. 51: 199-218.

Wilson, E. O., and W. H. Bossert. 1971. A primer of population biology. Sinauer Associates, Sunderland, Massachusetts.

Zar, J. H. 1999. Biostatistical analysis, 4th ed. Prentice-Hall, Upper Saddle River, New Jersey. 
